\title{
The Correlation Between Political Socialization and Sexual Activity among American Adolescents
}

\author{
Jacqueline T. Chui ${ }^{1}$, Maura Large ${ }^{1}$ and Sean McGrath ${ }^{1}$ \\ ${ }^{1}$ Chadwick School, Palos Verdes Peninsula, CA 90274
}

\section{ABSTRACT}

In the past half-century, culture in the United States has experienced a significant shift in the acceptance of casual sex. On the grounds of educational institutions, students have come to engage more freely with "hookup culture." For professional-minded individuals, engaging in no-strings-attached relationships have benefitted their careers while not having to sacrifice intimate moments with others. During such a politically-charged moment in this nation's history, when ideological polarization is so prevalent, it is important to ask just how much adolescents, who are on the cusp of engaging in sexual activity, are informed by the political circumstances that exist within their surroundings and daily lives. A review of literature on these intersectional subjects shows that, though both have been considered separately, little has been done in comparative analysis to determine the relationship in adolescents between the two. This paper seeks to determine whether sexual activity of individuals aged 14-18 is correlated at all to the socializing effects of the political ideologies within their upbringings. Ultimately, findings within this paper indicate that high-school students from "more conservative states" generally engage in sexual activity much earlier in age and are currently more sexually active when compared to high-school students from "more liberal states."

\section{Historical Background}

The social acceptance of casual sex originated within the 1960s-1970s. Since then, sexual promiscuity has come to dominate America's social and popular culture. Pivotal moments in the late twentieth century of American history have established a widespread culture of sexual appreciation that has come under close academic review only recently with the start of the twenty-first century.

The modern history of casual sex in American culture can be divided into three distinct periods of history. The first movement is argued to have occurred during the 1970s with the ruling of Roe vs Wade, which legalized abortion; birth control also became more widely distributed within this time frame upon its invention in the 1960s (Tyrer). In this period of time, conventional commitments were no longer requirements for courtship, and sexual activity became much more casual, prompting teenagers to become more likely to attend social gatherings (Bogle 775778). The national legalization of abortion not only led to increased rates of sexual activity, but also caused the rate of contracting sexually-transmitted diseases to skyrocket (Klick 407-433). Public panic heightened yet again in the 1980s during a second sexual movement alongside the HIV/AIDS epidemic, a period in which the risk of disease and death continued to shadow the topic of casual sex (Martin 578-581). The most recent sexual movement involves the formation of the \#MeToo Movement in 2017, a national development protesting against sexual assault and harassment in the workplace (Mendes 236-246). The high profile status of this digital feminist movement sparked conversation about physical abuse and sexual harassment not just through social media platforms, but in the academic world as well (Abbassi; Gale; Thurston 48-53).

Ultimately, all three movements were considered to have greatly shaped the American public's view in regards to casual sexual encounters, placing a large emphasis on the physical health risks associated with any sexual encounter. Coupled together, these events influenced and arguably even staged the in-depth research regarding casual 
sex that has occurred since the current millennium. What is often overlooked, however, are the inherent political ties present at each step in the development of the US population's views on sexual activity.

\section{Literature Review}

Within academic literature, sexual intercourse among adolescents has largely been referred to as a "problem behavior" due to the accompanying physical and mental health implications. As such, the predictors of teenage sexual activity have been researched mainly with the goal of helping reduce sex rates among adolescents. However, little research has been conducted regarding other indicators_-such as political ideology_-which do not directly influence these "problem behaviors."

\section{0s: Analyzing the General Predictors of Sexual Activity among Adolescents}

Numerous studies and surveys have been conducted particularly in response to the upsurge of "hookup culture" on school campuses. For many, the physical health risks associated with this widespread sex culture is concerning, and thus, the predictors of sexual-hookup culture have been heavily examined in an attempt to stunt the growth of this culture. As it pertains to sexually active college students, the influence of institutional religious involvement on hookup culture has been examined with research indicating that female Catholics exhibit higher rates of sexual activity than individuals of any other religious affiliation groups or religiously unaffiliated individuals (Brimeyer 462-473; Burdette 535-551). Other demographic trends include the analysis of socio-economic status and race among sexually active American teenagers involved with campus hookup culture (Brimeyer 462-473; Ethier 1393-1397).

The general consensus from such research is that caucasian males of high socio-economic status exhibit higher rates of sexual activity than individuals of an ethnic minority or lower socio-economic status. Perhaps the most studied predictor of sexual activity, many researchers have studied the gender differences in participation and attitudes towards casual sex, many using women as a controlled group for research (England, 1327-1338; Fjaer 960-981; Recalde; Reid 545-568). Most of these studies share similar findings about the differences in attitudes towards hookup culture between different genders. Research indicates that females are more harshly judged for promiscuity and typically much more interested in seeking emotional connections than that of their male counterparts, discouraging them from involvement with campus hookup culture.

\section{Political Party Affiliation as a Predictor of Sexual Attitudes among Adults}

Among the intense academic research that has ensued in the past half century in regards to the general predictors of sexual activity, the influence of Political Party Affiliation has just recently been studied as a predictor for sexual attitude among adults_ _ the general consensus being that the more politically conservative an individual is, the less sexually active he/she is (Arfer). In recent years, American conservatism has placed an emphasis on a more traditional set of social values; conversely, American liberalism places an emphasis on more progressive social values. Today, U.S. politics is ruled by two major political parties: the Republican Party and the Democratic Party, with the Democratic Party acting as the more progressive body (Levendusky). When comparing the relative engagement in sexual activity among the two political parties, premarital sex was found to have been more "acceptable" among registered Democrats (Fried). In fact, a 2003 Gallup poll found that $80 \%$ of liberals viewed premarital sex as "acceptable" in comparison to the $42 \%$ of conservatives (Gallup).

By analyzing data collected from 1991-1996 among 9405 married Americans, Democrats were found to have been 4\% more likely to cheat on their spouses (Fried). Within this same time frame, 5018 males were questioned, "Have you ever had sex with a person you paid or who paid you for sex?" $17.8 \%$ of the Democrats responded "yes," while only $13.9 \%$ of the Republicans responded "yes" (Fried). Furthermore, a 2006 survey consisting of 634 
interviewees found that $11 \%$ of Democrats have felt homosexual feelings in comparison to the 5\% of Republicans (Fried). Ultimately, the rates of casual sex and the variety of sexual activity are generally higher and more varied among this country's Democrats in comparison to the Republicans.

\section{Political Socialization}

An argument is to be made regarding American teenagers today and their lack of political engagement. It has been concluded that American adolescents under the age of 18 can be immune to any socializing effects of the political ideologies that dominate their upbringings. This type of civic disengagement is argued to have been a result of a newfound political cynicism regarding national politics (Putnam 132).

The inception of the twenty-first century marked a watershed moment in which digital technology became globalized and increasingly widespread. For centuries, media has influenced social attitudes, political education, and civic engagement, especially among young students. However, the recent establishment of an online media culture has led to an exponential growth of infotainment and tabloidization that has notably replaced the journalistic credibility that once dictated media (Banaji 411). Sensationalism and propaganda have eroded traditional forms of political education and allowed fake news to proliferate, dominating much of the digital information existing today. Young adolescents have evolved to become our nation's most frequent consumers of the media, yet they are also the most exposed to the type of fabricated information. Viewing this type of deliberate disinformation can foster negative feelings of inefficacy and cynicism in relation to the world of politics (Balmas 430). Underlying this conjecture is the suspicion that young Americans today believe national politics to be ineffectual or slow (Torney-Purta et al. 380).

This can be evidenced by the decreasing participation of young voters in our nation's most recent elections. For example, about half of the eligible 18-29 year olds voted in elections during the early 1970s compared to the one third that voted in 2000 (Galston 263). Furthermore, a 2006 National Civic and Political Health Survey found that only 27\% of young Americans aged 15-25 years old followed current events/public affairs (Lopez 17). Such data suggests that the American youth is essentially becoming less engaged in politics.

As a review of literature suggests that interest in political participation among young Americans is rapidly decreasing, I must note that there is the possibility amongst American adolescents in that political ideology might not inform whether they are more likely to engage in sexual activity.

\section{Concluding the Literature Review}

All in all, a review of literature suggests that the rise of a casual sex culture among this nation's young adolescents has undergone great academic review and analysis. Likewise, the influence of political party affiliation on adult sexual behavior has also been studied in the academic world. However, the influence of political ideology on this nation's young adolescents, in respect to their engagement in sexual activity, has remained largely disregarded in the world of research. As such, the purpose of this paper is to bridge this gap by addressing wether a correlation exists between the political ideologies found within an adolescent's upbringing and their level of engagement in casual sex. Nevertheless, a review of literature does suggest the possibility that no correlation is to be found between an adolescent's sexual behaviors and the political ideologies that dominate his/her daily life.

\section{Hypothesis}

It is predicted that there will be a positive correlation between blue-leaning states and higher rates of sexual activity. Research up to this point is suggestive that the more liberal policies of blue-leaning states will correlate to a higher rate of sexual activity among adolescents whose upbringings are influenced by more liberal ideologies. On the other hand, more conservative policies of red-leaning states will lead to more conservative sexual attitudes among teenagers within such atmospheres. As such, the following hypothesis has been constructed and will be measured through the 
course of this study: Adolescents in blue-leaning states engage in higher rates of sexual activity when compared to adolescents in red-leaning states.

\section{Methods}

\section{Conceptual Framework}

This study will closely replicate a design utilizing a "most-similar" comparative approach as a method for analysis (Finifter). Comparative approaches in the discipline of political sciences refer to the feature-by-feature comparison of methodological issues that arise in the systematic analysis of a select number of cases (small "N"). A handful of cases sharing nearly identical variables - except for the outcome (dependent variable) — are examined thoroughly. The focus is placed on a small number of cases rather than a large number of cases for the purpose of more in-depth analysis.

Under this research design, four cases (i.e. percent of high school males/females ever had sexual intercourse and percent of high school males/females currently sexually active) will serve as the selected dependent variables, each offering different outcomes for the independent variable. In particular, this study will focus on the independent variables of political ideology in order to determine whether there is any correlation between the sexual activity of highschoolers and the political socialization surrounding their upbringings. A temporal mean of 2015-2018's voter registration levels will be calculated and considered alongside percentages for these specified four cases of high school sexual activity in order to determine whether there is correlation between the independent and dependent variables.

To conduct a small $\mathrm{N}$ most similar analysis, two data tables will be compiled crossing all Democratic- and Republican-leaning states against their data for the four dependent variable cases listed above (Figures 3A \& 3B). The averages for all statistics will be averaged among blue states and red states separately (Figure 4), and a resultant table will be developed with "Yes" and "No" outputs (Figure 5). "Yes" will represent whether the blue state or red state group had a greater average percentage than the other in reference to each individual dependent variable case. In doing so, it can be found whether blue states or red states most closely align with these dependent variables.

\section{Operationalizing and Measuring Sexual Activity}

For the purposes of this research, sexual activity has been operationalized as sexual intercourse as surveyed by the Center for Disease Control and Prevention (CDC) in their annual Youth Risk Behavior Surveillance Survey (YRBSS). Although heterosexuality vs homosexuality, and sexual contact by gender were tracked in this survey, the generic wording of the CDC questionaire would suggest that the interviewees who answered affirmatively would be individuals who engage in genital-to-genital sexual contact, versus others who may have only had oral sex or foreplay.

This study primarily utilizes data from the CDC's 2017 Youth Risk Behavior Surveillance Survey (YRBSS) for the measure of sexual activity among high schoolers in the United States, as this data set is the most recently published YRBSS. In particular, the data set's results were gathered from September, 2016-December, 2017 and released in June, 2018.

Compiled by the CDC, these data sets have contributed to research and discussion on what are considered "risk behaviors:" inadequate physical activity, unhealthy nutrition, alcohol and drug use, tobacco use, behavior that contributes to physical injuries and violence, and sexual behaviors contributing to unintended pregnancies and STDs. Since 1991, this survey has been conducted by the CDC, been retested for inefficiencies, and held up against critiques for its reliable and generous data collection methods. Data collected varies by sex, race/ethnicity, grade, across states, and across large urban school districts. For this study, the survey's data sets regarding sexual activity among highschoolers by state (Figures 3A \& 3B) particularly informed the research question reviewed in this study. Students involved in the YRBSS completed the self-administered questionnaire during one class period. The 2017 YRBSS's standard questionnaire contained 89 questions, and 14,956 of these surveys were completed in 144 schools nationwide. 
Data collected from the CDC's annual YRBSS is then published online in state profile reports released by The Sexuality Information and Education Council of the United States (SIECUS). SIECUS is a non-profit organization that relies heavily on the data provided by the CDC's annual YRBSS for data regarding teenage sexual activity. Unlike the CDC, SIECUS provides additional information concerning the larger context of the laws and federal funding streams within each state and how such variables may contextualize the broader trends of sex education and rates of teenage sexual activity.

Within the data published by SIECUS's annual state profile reports, four cases in particular were identified as consistently reported for states identified as the top 10 "most-Democratic and "most-Republican" leaning states. In particular, data points were gathered for the following questions from the CDC'S YRBSS:

1. \% High-school males reported ever having had sexual intercourse

2. \% High-school females reported ever having had sexual intercourse

3. $\%$ High-school males reported being currently sexually active

4. \% High-school females reported being currently sexually active

\section{Operationalizing and Measuring Political Ideology}

For this particular paper, state-wide political affiliation of all registered voters will serve as a measurement for the political leaning of a state. Voter registration was gathered from years 2015-18 through data sets provided by Gallup, an American analytics and advisory company based in Washington D.C. The ten most-liberal-identified as "most Democratic" - and ten most-conservative - identified as "most Republican"- -states were isolated by the percentage point delta between registered Democrats and Republicans:

Democratic advantage in each state is calculated annually by taking the percentage of State-Registered Democrats subtracted by the percentage of State-Registered Republicans. Conversely, Republican advantage in each state is calculated annually by taking the percentage of State-Registered Republicans subtracted by the percentage of StateRegistered Democrats. States with the greatest "democratic advantage" or "republican advantage" are considered the "most democratic" or "most republican states."

Two data tables were created for statewide voter registration, analyzing years 2015-18 and measuring the state party leaning for the "most-Democratic" and "most-Republican" states (Figures $1 \& 2$ ). The one state that lacked voter registration information for a single year-Delaware, 2017-was retained in the data set for this paper. Political efficacy does not often shift drastically in small time frames, and as such, a single year's missing data point would not offer enough reason to invalidate the state's place in this study.

The Gallup Results for the 2015-2018 Statewide Voter Registration Surveys are based on telephone interviews from each individual year. Samples for each year's survey range from 160,000-180,000 adults, ages 18 and older, living in all 50 U.S. states. Margins of error for all surveys conducted in each individual state are no greater than $6 \%$. Telephone numbers were selected randomly.

In order to analyze these data sets, the average percentage delta was recorded for each state over the four year period of 2015-2018. The temporal mean of state-wide voter registration between years 2015-2018 are utilized to ensure greater statistical accuracy as the percentage of democratic advantage and republican advantage varies on a yearly basis. Moreover, these particular years were chosen as they were the closest in proximity to the sexual activity data provided by the SIECUS reports, which relied on the 2017 YRBSS. Simply analyzing data from previous election years would have made the relationship between voter registration and sexual activity data sets tenuous, and discounted those who are not particularly political in their everyday lives. Yearly registration data offers insight on the prevalence of political ideology and thus, the potential magnitude of its socializing effect on adolescents.

Additionally, the percentage delta in Republican vs. Democratic registration was chosen as the singular measure of most general political affiliation by state as each state is subject to citizenry that identifies in both directions. 
To singularly value a state by either its Republican or Democratic registration alone would invalidate the impact of opposing ideologies and their impacts on the populaces.

Once the average Democratic/Republican advantages of the top ten "most-Democratic" and "most-Republican" states are calculated, the states will be ranked by their average percentages from greatest advantage to least advantage on a scale of 1-10 (Figures $1 \& 2$ ). The data will then be cross-referenced with the YRBSS's sexual activity data in order to determine most-similar variables, if any.

\begin{tabular}{|l|l|r|r|r|r|r|}
\hline & STATE & AVERAGE & $\mathbf{2 0 1 5}$ & $\mathbf{2 0 1 6}$ & $\mathbf{2 0 1 7}$ & $\mathbf{2 0 1 8}$ \\
\hline $\mathbf{1}$ & Massachusetts & $25.88 \%$ & $18.60 \%$ & $24.90 \%$ & $31 \%$ & $29 \%$ \\
\hline $\mathbf{2}$ & Vermont & $23.55 \%$ & $21.70 \%$ & $25.50 \%$ & $22 \%$ & $25 \%$ \\
\hline $\mathbf{3}$ & Maryland & $22 \%$ & $15 \%$ & $23.20 \%$ & $28 \%$ & $23 \%$ \\
\hline $\mathbf{4}$ & Hawaii & $21.63 \%$ & $20.80 \%$ & $18.70 \%$ & $22 \%$ & $25 \%$ \\
\hline $\mathbf{5}$ & New York & $21.38 \%$ & $18.40 \%$ & $21.10 \%$ & $23 \%$ & $23 \%$ \\
\hline $\mathbf{6}$ & California & $18.70 \%$ & $15.50 \%$ & $18.30 \%$ & $21 \%$ & $20 \%$ \\
\hline $\mathbf{7}$ & Connecticut & $16.70 \%$ & $10.50 \%$ & $18.30 \%$ & $19 \%$ & $19 \%$ \\
\hline $\mathbf{8}$ & Illinois & $15.43 \%$ & $10.80 \%$ & $17.90 \%$ & $17 \%$ & $16 \%$ \\
\hline $\mathbf{9}$ & Delaware & $12.70 \%$ & $5.80 \%$ & $19.30 \%$ & & $13 \%$ \\
\hline $\mathbf{1 0}$ & Washington & $12.30 \%$ & $9.10 \%$ & $10.10 \%$ & $15 \%$ & $15 \%$ \\
\hline
\end{tabular}

Figure 1: Most-Democratic States ranked by statewide voter registration information from years 2015-18, as provided by Gallup

\begin{tabular}{|l|l|r|r|r|r|r|}
\hline STATE & AVERAGE & $\mathbf{2 0 1 5}$ & $\mathbf{2 0 1 6}$ & $\mathbf{2 0 1 7}$ & $\mathbf{2 0 1 8}$ \\
\hline $\mathbf{1}$ & Wyoming & $32.15 \%$ & $31.80 \%$ & $33.80 \%$ & $29 \%$ & $34 \%$ \\
\hline $\mathbf{2}$ & Utah & $28.13 \%$ & $29.90 \%$ & $27.60 \%$ & $27 \%$ & $28 \%$ \\
\hline $\mathbf{3}$ & Idaho & $24 \%$ & $30 \%$ & $26.20 \%$ & $22 \%$ & $16 \%$ \\
\hline $\mathbf{4}$ & North Dakota & $23.68 \%$ & $20.80 \%$ & $20.90 \%$ & $28 \%$ & $25 \%$ \\
\hline $\mathbf{5}$ & South Dakota & $16.63 \%$ & $15.80 \%$ & $22.70 \%$ & $17 \%$ & $11 \%$ \\
\hline $\mathbf{6}$ & Alabama & $16.58 \%$ & $17.30 \%$ & $17 \%$ & $15 \%$ & $17 \%$ \\
\hline $\mathbf{7}$ & Alaska & $16.18 \%$ & $17.20 \%$ & $8.50 \%$ & $21 \%$ & $18 \%$ \\
\hline $\mathbf{8}$ & Kansas & $13.75 \%$ & $13.10 \%$ & $16.90 \%$ & $14 \%$ & $11 \%$ \\
\hline $\mathbf{9}$ & Oklahoma & $13.28 \%$ & $13.40 \%$ & $17.70 \%$ & $14 \%$ & $8 \%$ \\
\hline $\mathbf{1 0}$ & Montana & $12.88 \%$ & $14.40 \%$ & $16.10 \%$ & $14 \%$ & $7 \%$ \\
\hline
\end{tabular}

Figure 2: Most Republican States ranked by statewide voter registration information from years 2015-18, as provided by Gallup

\section{Results}

After conducting a series of tests, the following results were obtained. For the purpose of concision, dependent variables in the data tables below will be identified as: 
N1: Percentage (\%) of high-school males reported ever having had sexual intercourse

N2: Percentage (\%) of high-school females reported ever having had sexual intercourse

N3: Percentage (\%) of high-school males reported being currently sexually active

N4: Percentage (\%) of high-school females reported being currently sexually active

\begin{tabular}{|l|l|r|r|r|r|}
\hline & STATE & N1 & N2 & N3 & \multicolumn{2}{|c|}{ N4 } \\
\hline $\mathbf{1}$ & Wyoming & $41.3 \%$ & $42.5 \%$ & $29.1 \%$ & $33.7 \%$ \\
\hline $\mathbf{2}$ & Utah & - & - & - & - \\
\hline $\mathbf{3}$ & Idaho & $35.5 \%$ & $34.8 \%$ & $24.7 \%$ & $25.5 \%$ \\
\hline $\mathbf{4}$ & North Dakota & $36.6 \%$ & $36.6 \%$ & $26.61 \%$ & $27.9 \%$ \\
\hline $\mathbf{5}$ & South Dakota & $39.4 \%$ & $34.9 \%$ & $28.1 \%$ & $26.6 \%$ \\
\hline $\mathbf{6}$ & Alabama & $49.5 \%$ & $43.6 \%$ & $34.8 \%$ & $34.9 \%$ \\
\hline $\mathbf{7}$ & Alaska & $35.3 \%$ & $38.7 \%$ & $19.7 \%$ & $30.9 \%$ \\
\hline $\mathbf{8}$ & Kansas & $35.8 \%$ & $35.1 \%$ & $25.3 \%$ & $27.4 \%$ \\
\hline $\mathbf{9}$ & Oklahoma & $42.9 \%$ & $42.8 \%$ & $24 \%$ & $32.9 \%$ \\
\hline $\mathbf{1 0}$ & Montana & $41.6 \%$ & $44.8 \%$ & $28.9 \%$ & $34.2 \%$ \\
\hline
\end{tabular}

Figure 3A: Percentage (\%) breakdown of dependent variables "N" in "most-Republican" states according to the 2018 SIECUS state profiles

\begin{tabular}{|l|l|r|r|r|r|}
\hline & STATE & N1 & N2 & N3 & N4 \\
\hline $\mathbf{1}$ & Massachusetts & $35.8 \%$ & $34.9 \%$ & $23.7 \%$ & $26.3 \%$ \\
\hline $\mathbf{2}$ & Vermont & - & - & $32.4 \%$ & $28.8 \%$ \\
\hline $\mathbf{3}$ & Maryland & $33.9 \%$ & $29.7 \%$ & $21.8 \%$ & $22.2 \%$ \\
\hline $\mathbf{4}$ & Hawaii & - & - & $16.3 \%$ & $21.5 \%$ \\
\hline $\mathbf{5}$ & New York & $29.4 \%$ & $31.6 \%$ & $19.7 \%$ & $24.5 \%$ \\
\hline $\mathbf{6}$ & California & $36.6 \%$ & $27.9 \%$ & $24.2 \%$ & $20.9 \%$ \\
\hline $\mathbf{7}$ & Connecticut & $34.3 \%$ & $32.4 \%$ & $24.4 \%$ & $26.3 \%$ \\
\hline $\mathbf{8}$ & Illinois & $38.4 \%$ & $37.8 \%$ & $26.5 \%$ & $29.8 \%$ \\
\hline $\mathbf{9}$ & Delaware & $46.9 \%$ & $43.9 \%$ & $32 \%$ & $34.7 \%$ \\
\hline $\mathbf{1 0}$ & Washington & - & - & - & - \\
\hline
\end{tabular}

Figure 3B: Percentage (\%) breakdown of dependent variables " $N$ " in "most-Democratic" states according to the 2018 SIECUS state profiles 


\begin{tabular}{|l|rrr|rr|r|}
\hline & N1 & N2 & N3 & \multicolumn{2}{|c|}{ N4 } \\
\hline MOST- REPUBLICAN STATES & \multicolumn{3}{|c|}{$39.8 \%$} & $39.3 \%$ & $26.8 \%$ & $30.4 \%$ \\
\hline MOST- DEMOCRATIC STATES & & $36.5 \%$ & $34.0 \%$ & $24.6 \%$ & $26 . \%$ \\
\hline
\end{tabular}

Figure 4: Average percentage (\%) breakdown of dependent variables "N" in "most-Republican" and "most-Democratic" states according to the 2018 SIECUS state profiles

\begin{tabular}{|l|cc|cc|c|}
\hline & N1 & N2 & N3 & N4 \\
\hline MOST- REPUBLICAN STATES & & Yes & Yes & Yes & Yes \\
\hline MOST- DEMOCRATIC STATES & & No & No & No & No
\end{tabular}

Figure 5: Comparison of the average percentage (\%) breakdown of dependent variables "N" in "most-Republican" and "most-Democratic" states according to the 2018 SIECUS state profiles utilizing the Small-N most similar comparative method

\section{Discussion}

As illustrated in Figure 5, male and female high-school students of the "most-republican states" on average engage in sexual activity much earlier in age and are currently more sexually active when compared to the male and female high-school students of the "most-democratic states." Ultimately, these findings disprove my initial hypothesis which argues that adolescents living in the "most-democratic states" are more sexually active than those of the "most-republican states."

However, when closely examining Figure 4, one may find that the percentage points for all dependent "N" variables to be fairly close between the Republican and Democratic States. The percent margin of difference for N1 was just over 3\% while the percent margin of difference for $\mathrm{N} 2$ was just over $5 \%$. N3 exhibited a percent difference less than $3 \%$, and $\mathrm{N} 4$ exhibited a percent difference just over $6 \%$.

A strong progression in percentage points does not exist across the rankings of the "most-Democratic" and "most-Republican" states within this study. For example, within the state of Wyoming—ranked the "most-Republican" state-approximately $41.3 \%$ high-schools males reported having had sexual intercourse. However, Oklahoma-ranked the ninth "most-Republican" state-exhibited a rate of $42.9 \%$, a rate higher than that of Wyoming. Among both the Republican and Democratic states, no clear pattern can be identified in regards to teenage sexual activity. Male teenagers in both democratic and republican states engage in sexual intercourse much earlier in life when compared to their female counterparts. However, there exist more female teenagers that are currently sexually active in contrast to their male counterparts in republican and democratic states.

All in all, there exists a general trend within this research study indicating that male and female teenagers in Republican-states exhibit higher rates of sexual activity than in Democratic-states. Gender carries no clear bearing over engagement of sexual activity in Democratic states nor Republican states.

\section{Limitations}

Limitations in Using the CDC's YRBSS to Measure Rates of Teenage Sexual Activity 
Within the context of this paper, sexual activity is operationalized and measured through data previously compiled from the CDC's 2017 YRBSS. While the survey's sampling size was relatively large, involving 14,956 students involved and stretching across 40+ states nationwide, the survey's data is not representative of the nation's entire teenage population. In fact, further investigation of this subject matter should involve data from a wide variety of sources.

Moreover, although the CDC's YRBSS was extensive in that it contained 89 questions, the wording of these questions were often vague and susceptible to various interpretations. For example, the term "sexually active" can pose a series of meanings. A student could view the term "sexually active" as behavior including oral sex or foreplay and not necessarily only of a coital nature.

Additionally, information provided by the CDC regarding rates of sexual activity is much more varied among the "most-republican states" when compared to the "most-democratic states." For example, while Utah was the only republican state in this study that did not report information regarding teenage sexual activity to the CDC, Vermont, Hawaii, and Washington are of the democratic states within this paper that did not report all of their findings to the CDC. This discrepancy leaves a larger margin of error for data provided by the CDC on behalf of the "most-democratic states" in contrast to the data provided on behalf of the "most-republican states."

Furthermore, as the survey is distributed to thousands of students nationwide, the CDC is incapable of guaranteeing honest answering among all survey responders. It must be noted that there does exist the possibility that some of the YRBSS's responders fabricated information about their level of sexual activity in fear of reprisal or due to other motives.

Finally, given that a comparison of the percentage points between such states indicate a narrow margin of difference, one could posit that the results of this paper require further research from a wider variety of sources in addition to CDC's YRBSS to reaffirm this paper's conclusion that Republican states exhibit higher rates of sexual activity than Democratic states.

\section{Limitations in Employing the "Small-N" Comparative Method for Analysis}

In addition to the challenges involving the CDC's YRBSS, there exist complications in employing the "Small-N" most-similar comparative method as the methodology within this study. In comparative political research, this particular framework of research can be beneficial in that it simplifies resultant data into a mere two categories: Yes and No. However, treating the results as mere "Yes" and "No" outcomes can lead to oversimplification of raw data. Any additional factors that may lead to causal complexity or more nuanced explanations of the data provided by the CDC's YRBSS are difficult to determine in this comparative method for analysis. For this paper, this model allows a conclusion on potential correlation between the tested variables, but not any insight on a causal relationship.

Furthermore, causal generalizations are frequently made when a comparative method is employed as the method of analysis. For example, given the results within this study, one may simply claim that a more Republicanleaning state correlates to a higher rate of teenage sexual activity when compared to a more Democratic-leaning state. However, there are a multitude of factors that could influence the percentages of sexually active teenagers in the "most-Democratic" and "most-Republican" states that could skew the results of this study.

\section{Limitations in Using Registered Political Affiliation to Measure Political Leaning}

It should be noted that there are limitations in using voter registration as a measure of the prevalence of a political ideology by state as there are different systems and requirements in place, per state, that restrict individuals from voter registration. Voter suppression was found to have been a very pressing concern in the 2018 midterm election.For example, in the state of New Hampshire, strict voter registration laws in 2018 prevented those who registered within 30 days of an election to prove a place of residency, a requirement that particularly affected new college-aged voters (Mcdermott). Furthermore, approximately 53,000 voters' registration were called into question and placed in “pending 
status" by the state secretary of Georgia (Keenan). The argument was that minor misspellings or missing hyphens on the voter registration forms could lead to identification issues in future elections. Another voter suppression law was upheld in the 2018 election by North Dakota when the U.S. Supreme Court Upheld that all registered voters must present identification with proof of residence. However, this law disproportionately disadvantaged the Native American population (approximately 5,000 eligible voters) in addition to many more voters (Astor). Nationwide, it was claimed that in the 2016 presidential election, roughly $3 \%$ of voters waiting in line at election polls were unable to vote due to long lines (Fortier 7). All in all, there exist complications in utilizing voter registration as a measurement of a state's political leaning.

Secondly, voter registration is only an estimate for understanding political socialization in adolescents. While this paper seeks to examine adolescents between the ages of 14-18, information regarding registered voters in the United States pertains to adults aged $18+$. Thus, this measure of political leaning does not actually have a direct relationship to the dependent variables that I have tested.

\section{Conclusion}

Though researchers have thoroughly examined the potential predictors of early engagement in sexual activity among teenagers in the United States, this paper sought to analyze a seldom-discussed predictor among researchers: the extent to which political ideologies within the upbringings amongst American adolescents correlate to their sexual activity. Disproving my initial hypothesis, the results of this study indicate that adolescents living in the "most-democratic states" are less sexually active than those of the "most-republican states." However, research conducted prior to the experiment in the literature review indicates that this nation's youth are not as politically engaged in comparison to past generations and may not be prone to political socialization.

Therefore it should be noted that in line with this political lethargy, the differences in percentages between red and blue states were not statistically significant and that further research should be conducted to further affirm this paper's findings. In order to establish a more concrete argument in regards to the relation between teenage sexual activity and political ideology, the following recommendations are made:

1. Future research should seek to question a larger sample size of students across the U.S. Though the information provided by the CDC proved extremely helpful in this study, the students involved represent a small fraction of the whole nation's adolescent population, and crucial information was missing from some states.

2. While the data within this study was compared by gender, future research should seek to explore other demographics, including race, age, socio-economic status, etc.

3. Though this study generally focused on heterosexual coital activity, future research should consider incorporating research on homosexual activity.

4. Future research should consider operationalizing and measuring political ideology using different means. Rather than generalizing entire states as "Democratic-leaning" or "Republican-leaning," future research could perhaps consider an individual's political leanings as a more accurate measure of political ideology.

This paper simply explores the correlation between teenage sexual activity and political ideology. It does not explore a cause-effect argument. Nevertheless, I still believe that this study can open a gateway in the research world, prompting researchers to analyze the correlation between political ideology and teenage sexual activity. 


\section{Acknowledgements}

I would like to take the time to thank my advisors Mrs. Maura Large and Mr. Sean McGrath for guiding me through this research process. They have been instrumental to the completion of this paper, and I am so grateful for all their help. I would also like to extend my gratitude to the Chadwick community as a whole. I have the utmost gratitude for this institution, and I can confidently say that I never would have found my passion for research had it not been for my time at Chadwick School.

\section{References}

Alabama State Profile: Fiscal Year 2018. Sexuality Information and Education Council of The United States, 2018, https://siecus.org/wp-content/uploads/2019/03/Alabama-FY18-Final-1.pdf

Alaska State Profile: Fiscal Year 2018. Sexuality Information and Education Council of The United States, 2018, https://siecus.org/wp-content/uploads/2019/03/Alaska-FY18-Final-1.pdf

Arfer, Kodi B., and Jason J. Jones. "American Political-Party Affiliation as a Predictor of Usage of an Adultery Website.” Archives of Sexual Behavior, vol. 48, no. 3, 12 July 2018, pp. 715-723., doi:10.1007/s10508-018-1244-1.

Astor, Maggie. "A Look at Where North Dakota's Voter ID Controversy Stands.” The New York Times, The New York Times, 19 Oct. 2018, www.nytimes.com/2018/10/19/us/politics /north-dakota-voter-identificationregistration.html.

Balmas, Meital. "When Fake News Becomes Real: Combined Exposure to Multiple News Sources and Political Attitudes of Inefficacy, Alienation, and Cynicism." Sage Journals, vol. 41, no. 3, 2012, pp. 430-454., doi:10.1177/0093650212453600.

Banaji, Shakuntala. "Young Citizens and New Media: Learning for Democratic Participation, by Peter Dahlgren." Journal of Information Technology \& Politics, vol. 5, no. 4, 2008, pp. 411-413., doi:10.1080/19331680802555002.

Bogle, Kathleen A. "The Shift from Dating to Hooking up in College: What Scholars Have Missed." Sociology Compass, vol. 1, no. 2, 2007, pp. 775-788., doi:10.1111/j.1751-9020.2007.00031.x.

Brimeyer, Ted M., and William L. Smith. "Religion, Race, Social Class, and Gender Differences in Dating and Hooking Up among College Students.” Sociological Spectrum, vol. 32, no. 5, 2012, pp. 462-473., doi:10.1080/02732173.2012.694799.

Brown, Larry K., et al. "Predictors of Condom Use in Sexually Active Adolescents." Journal of Adolescent Health, vol. 13, no. 8, 1992, pp. 651-657., doi:10.1016/1054-139x(92)90058-j.

Burdette, Amy M., et al. “'Hooking up' at College: Does Religion Make a Difference?” Journal for the Scientific Study of Religion, vol. 48, no. 3, 2009, pp. 535-551. JSTOR, www.jstor.org/stable/40405644.

California State Profile: Fiscal Year 2018. Sexuality Information and Education Council of The United States, 2018, https://siecus.org/wp-content/uploads/2019/03/California-FY18-Final-1.pdf 
Connecticut State Profile: Fiscal Year 2018. Sexuality Information and Education Council of The United States, 2018, https://siecus.org/wp-content/uploads/2019/03/Connecticut-FY18-Final-1.pdf

Delaware State Profile: Fiscal Year 2018. Sexuality Information and Education Council of The United States, 2018, https://siecus.org/wp-content/uploads/2019/03/Delaware-FY18-Final-1.pdf.

England, Paula, and Jonathan Bearak. "The Sexual Double Standard and Gender Differences In Attitudes toward Casual Sex among U.S. University Students.” Demographic Research, vol. 30, 2014, pp. 1327-1338. JSTOR, www.jstor.org/stable/246348237.

Ethier KA, Kann L, McManus T. Sexual Intercourse Among High School Students — 2 States and United States Overall, 2005-2015. MMWR Morb Mortal Wkly Rep 2018;66:1393-1397. DOI:

http://dx.doi.org/10.15585/mmwr.mm665152a1

Finifter, Ada W. Political Science II: The State of the Discipline. American Political Science Association, 1993.

Fjaer, Eivind Grip, et al. "'I'm Not One of Those Girls': Boundary-Work and the Sexual Double Standard in a Liberal Hookup Context." Gender and Society, vol. 29, no. 6, 2015, pp. 960-981., www.jstor.org/stable/43670031.

Fortier, John C., et al. Improving the Voter Experience: Reducing Polling Place Wait Times by Measuring Lines and Managing Polling Place Resources. BiPartisan Policy Center, 2018.

Fried, Joseph. Democrats and Republicans_-Rhetoric and Reality: Comparing the Voters in Statistics and Anecdotes. Algora Publishing, 2008.

Gale, Sara, et al. "The Impact of Workplace Harassment on Health in a Working Cohort.” Frontiers in Psychology, vol. 10, 24 May 2019, doi: 10.3389/fpsyg.2019.01181.

Gallup, George H. “Current Views on Premarital, Extramarital Sex.” Gallup.com, Gallup, 31 Jan. 2020, news.gallup.com/poll/8704/x.aspx.

Galston, William A. "Civic Education and Political Participation.” PS: Political Science \& Politics, vol. 37, no. 2, 2004, pp. 263-266., doi:10.1017/S1049096504004202.

Hawaii State Profile: Fiscal Year 2018. Sexuality Information and Education Council of The United States, 2018, https://siecus.org/wp-content/uploads/2019/03/Hawaii-FY18-Final-1.pdf

Idaho State Profile: Fiscal Year 2018. Sexuality Information and Education Council of The United States, 2018, https://siecus.org/wp-content/uploads/2019/03/Idaho-FY18-Final-1.pdf

Illinois State Profile: Fiscal Year 2018. Sexuality Information and Education Council of The United States, 2018, https://siecus.org/wp-content/uploads/2019/03/Illinois-FY18-Final-1.pdf

Jones, Jeffrey M. "Democratic States Exceed Republican States by Four in 2018." Gallup, Gallup, 22 Feb. 2019 , news.gallup.com/poll/247025/democratic-states -exceed-republican-states-four-2018.aspx. 
Jones, Jeffrey M. “GOP Maintains Edge in State Party Affiliation in 2016.” Gallup, Gallup, 30 Jan. 2017, news.gallup.com/poll/203117/gop-maintains- edge-state-party-affiliation-2016.aspx.

Jones, Jeffrey M. "Red States Outnumber Blue for First Time in Gallup Tracking." Gallup, Gallup, 3 Feb. 2016, news.gallup.com/poll/188969/red-states-outnumber -blue-first-time-gallup-tracking.aspx.

Jones, Jeffrey M. "State Partisanship Shifts Toward Democratic Party in 2017.” Gallup, Gallup, 1 Feb. 2018, news.gallup.com/poll/226556/state-partisanship-shifts-toward-democratic-party-2017.aspx.

Kansas State Profile: Fiscal Year 2018. Sexuality Information and Education Council of The United States, 2018, https://siecus.org/wp-content/uploads/2019/03/Kansas-FY18-Final.pdf

Keenan, Sean. "There Are 53,000 Pending Voters in Georgia. They Can Still Vote. Here's What You Need to Know." Atlanta Magazine, 16 Oct. 2018, www.atlantamagazine.com/ news-culture-articles/53000-pending-votersgeorgia-still-vote-what-to-know/.

Klick, Jonathan, and Thomas Stratmann. "The Effect of Abortion Legalization on Sexual Behavior: Evidence from Sexually Transmitted Diseases." The Journal of Legal Studies, vol. 32, no. 2, 2003, pp. 407-433., doi: $10.1086 / 377049$.

Levendusky, Matthew. The Partisan Sort: How Liberals Became Democrats and Conservatives Became Republicans. University of Chicago Press, 2010.

Lopez, Mark Hugo, et al. The 2006 Civic and Political Health of a Nation: A Detailed Look at How Youth Participate in Politics and Communities. Center for Information and Research on Civic Learning and Engagement (CIRCLE).

Martin, J L. "The Impact of AIDS on Gay Male Sexual Behavior Patterns in New York City.” American Journal of Public Health, vol. 77, no. 5, 1987, pp 578-581., doi: 10.2105/ajph.77.5.578.

Maryland State Profile: Fiscal Year 2018. Sexuality Information and Education Council of The United States, 2018, https://siecus.org/wp-content/uploads/2019/03/Maryland-FY18-Final.pdf

Massachusetts State Profile: Fiscal Year 2018. Sexuality Information and Education Council of the United States, 2018, https://siecus.org/wp-content/uploads/2019/03/Massachusetts-FY18-Final.pdf.

McDermott, Casey. "N.H. Voting Law SB3 Is Back in Court This Week -- Here's What You Need to Know.” New Hampshire Public Radio, 26 Aug. 2018, www.nhpr.org/post/nh -voting-law-sb3-back-court-week-heres-what-youneed-know\#stream/0.

Mendes, Kaitlynn, et al. "\#MeToo and the Promise and Pitfalls of Challenging Rape Culture Through Digital Feminist Activism.” European Journal of Women's Studies, vol. 25, no. 2, 2018, pp. 236-246., doi:

$10.1177 / 1350506818765318$.

Montana State Profile: Fiscal Year 2018. Sexuality Information and Education Council of The United States, 2018, https://siecus.org/wp-content/uploads/2019/03/Montana-FY18-Final.pdf 
New York State Profile: Fiscal Year 2018. Sexuality Information and Education Council of The United States, 2018, https://siecus.org/wp-content/uploads/2019/03/New-York-FY18-Final.pdf

North Dakota State Profile: Fiscal Year 2018. Sexuality Information and Education Council of The United States, 2018, https://siecus.org/wp-content/uploads/2019/03/North-Dakota-FY18-Final.pdf

Oklahoma State Profile: Fiscal Year 2018. Sexuality Information and Education Council of The United States, 2018, https://siecus.org/wp-content/uploads/2019/03/Oklahoma-FY18-Final.pdf

Putnam, Robert D. Bowling Alone: The Collapse and Revival of American Community. Simon and Schuster, 2000.

Recalde, Camila Tili, "Keeping It Casual: A Sexual Ethics for College Campus Hook Up Culture" (2016). Honors Theses - All. 1587. https://wesscholar.wesleyan.edu/etd_hon_theses/1587

Reid, Julie A., et al. "Casual Hookups to Formal Dates: Refining the Boundaries of the Sexual Double Standard." Gender and Society, vol. 25, no. 5, 2011, pp. 545-568. JSTOR, www.jstor.org/stable/23044172.

South Dakota State Profile: Fiscal Year 2018. Sexuality Information and Education Council of the United States, 2018, https://siecus.org/wp-content/uploads/2019/03/South-Dakota-FY18-Final.pdf

Thurston, Rebecca C., et al. “Association of Sexual Harassment and Sexual Assault With Midlife Women's Mental and Physical Health.” JAMA Internal Medicine, vol. 179, no. 1, Jan. 2019, pp. 48-53., doi:10.1001/jamainternmed.2018.4886.

Torney-Purta, Judith, et al. "Trust in Government-Related Institutions and Political Engagement among Adolescents in Six Countries.” Acta Politica, vol. 39, no. 4, 13 Dec. 2004, pp. 380-406., doi:10.1057/palgrave.ap.5500080.

Tyrer, Louise. "Introduction of the Pill and Its Impact." Contraception, vol. 59, no. 1, 1999, doi:10.1016/s00107824(98)00131-0.

Utah State Profile: Fiscal Year 2018. Sexuality Information and Education Council of The United States, 2018, https://siecus.org/wp-content/uploads/2019/03/Utah-FY18-Final.pdf

Washington State Profile: Fiscal Year 2018. Sexuality Information and Education Council of The United States, 2018, https://siecus.org/wp-content/uploads/2019/03/Washington-FY18-Final.pdf

Wyoming State Profile: Fiscal Year 2018. Sexuality Information and Education Council of The United States, 2018, https://siecus.org/wp-content/uploads/2019/03/Wyoming-FY18-Final.pdf

Youth Risk Behavior Surveillance - United States, 2017. 8th ed., vol. 67, Centers for Disease Control and Prevention, 2018, https:/www.cdc.gov/healthyyouth/data/yrbs/pdf/2017/ss6708.pdf.

Vermont State Profile: Fiscal Year 2018. Sexuality Information and Education Council of The United States, 2018, https://siecus.org/wp-content/uploads/2019/03/Vermont-FY18-Final.pdf 